\title{
Expertise Regarding Dental Management of Oral Cancer Patients Receiv- ing Radiation Therapy Among Western Australian Dentists
}

\author{
AM Frydrych*, LM Slack-Smith, JH Park and AC Smith \\ School of Dentistry, The University of Western Australia, Perth, Western Australia
}

\begin{abstract}
Objectives: Dental care forms an important part of the multidisciplinary management of oral cancer patients. The aim of this study was to examine actual and self-perceived knowledge and clinical expertise regarding dental management of oral cancer patients receiving radiation therapy among Western Australian general dentists.

Materials and Methods: An invitation to participate in a web-based questionnaire was emailed to 1095 dentists registered with the Australian Dental Association (ADA), WA branch. To assess dentists' knowledge and expertise, actual and perceived knowledge was investigated. Information regarding type of practice, practice location, year of graduation and number of oral cancer patients treated in the preceding 12 months was also obtained.

Results: One hundred and ninety one dentists responded to the survey. General dentists who took part in the study appeared to possess some knowledge regarding dental management of oral cancer patients treated with radiation therapy. The majority of responders however identified deficiencies in their knowledge and willingness to participate in continuing education programs.

Conclusion: In view of the rising incidence of oral cancer in Western Australia, efforts should be made to provide more clinically relevant training to dentists in this area.
\end{abstract}

Keywords: Dental care, dentists, expertise, oral cancer.

\section{INTRODUCTION}

In Australia, over 2000 new cases (ICD10 codes: C00$\mathrm{C} 06$ \& $\mathrm{C} 09-\mathrm{C} 10)$ of oral squamous cells carcinoma (SCC) (Fig. 1) are diagnosed annually, and the incidence is rising [1]. Of these cases, about 300 are reported in Western Australia annually [2].

The aetiology of oral SCC is related to tobacco and alcohol use, dietary micronutrient deficiency, human papilloma virus and in the case of the lip, solar irradiation [3]. It has been hypothesised that increased exposure to risk factors such as alcohol use and changing patterns of HPV associated cancers may be responsible for the rising incidence of oral SCC in Australia [4]. Patients with early disease (Stage I\&II) are usually treated with single modality treatment (either surgery or radiation therapy), while patients with advanced disease (stage III\&IV) require a combined approach such as extensive surgery and radiotherapy or chemo-radiation $[5,6]$.

Patient awareness of oral cancer, its signs, symptoms and risk factors is believed to be important in increasing chances of early disease detection and in facilitating behavioural modifications which limit exposure to known risk factors [79]. Studies which have examined patients' knowledge regarding oral cancer signs, symptoms and risk factors, have

*Address correspondence to this author at the School of Dentistry (512), The University of Western Australia, 35 Stirling Highway, CRAWLEY Western Australia 6009; Tel: +618 9346 7670; Fax: +618 9346 7666; Email: agnieszka.frydrych@uwa.edu.au shown that patients possess limited knowledge and that further educational interventions are required $[8,9]$. Dentists in particular need to play a more active role in patient education as research suggests that currently their role is inadequate $[7,8]$.

Unfortunately treatment of oral SCC is associated with significant short and long term complications including: mucositis (Fig. 2), dysguesia, dysphagia, weight loss, malnutrition, hypo-salivation, increased risk of dental caries (Fig. 3), increased risk of progression of periodontal disease, dental hypersensitivity, infections (Fig. 4), mucosal atrophy, trismus, neuropathic pain, and osteoradionecrosis (Fig. 5) [1017]. Dentists are often involved in the prevention and management of these complications. Efforts are made to minimize the risk of complications through the development of new therapies such as intensity-modulated radiation therapy $[5,18-20]$; use of cytoprotective agents [18-21]; and the multidisciplinary approach to treatment allowing, for example, the dental team to ensure the patient is dentally fit prior to commencement of cancer treatment and is able to maintain an optimal level of oral health in the challenging, dry mouth environment [22].

Dental input into the management of oral SCC patients normally consists of three phases [23]:

\section{Pre-Treatment Dental Work-Up}

The most important aims of pre-treatment dental work-up are to enable the patient to understand the oro-dental implications of their cancer treatment; maintain life long, optimal level of oral health and prevent osteoradionecrosis, the risk 


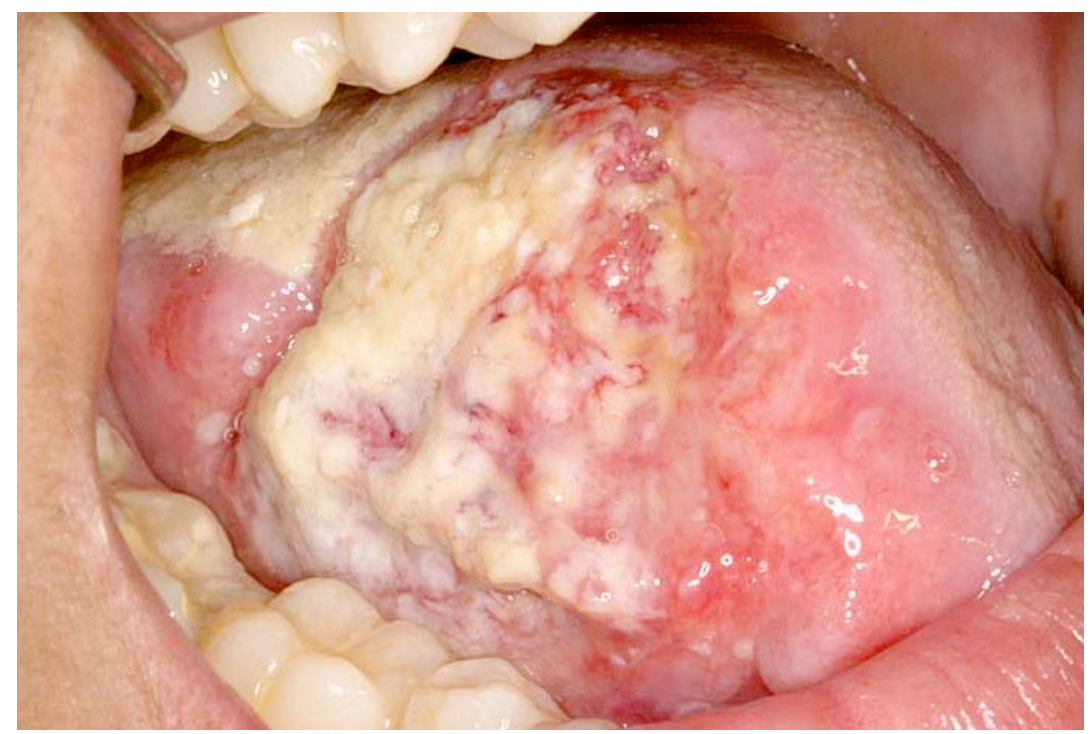

Fig. (1). SCC of the tongue.

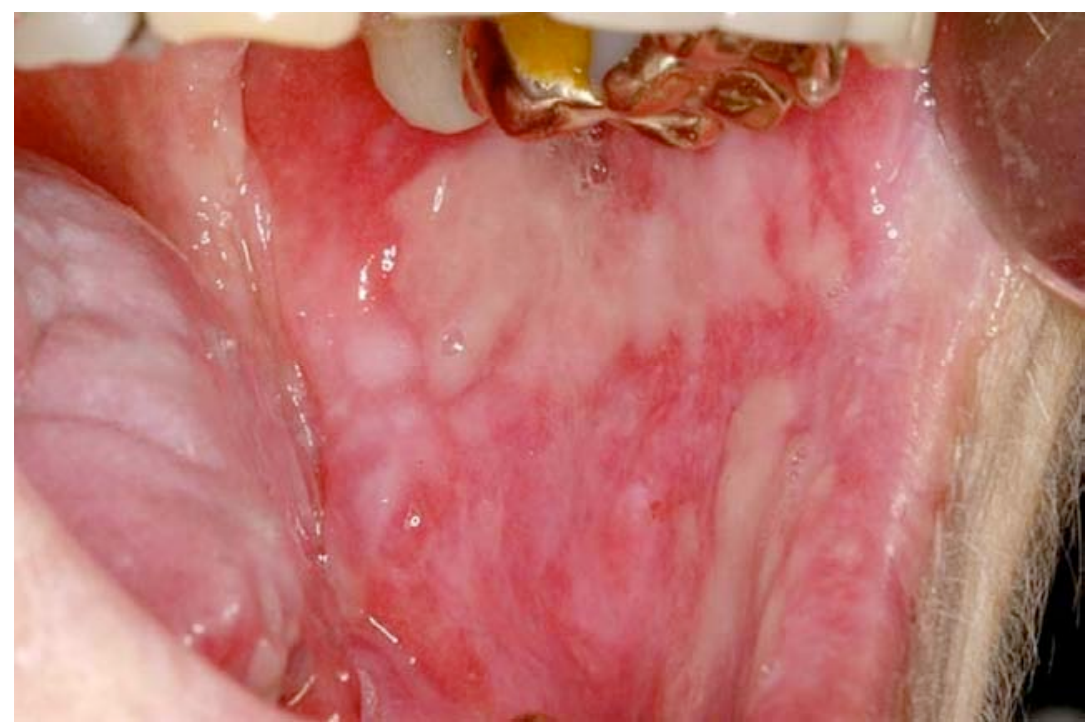

Fig. (2). Radiation mucositis.

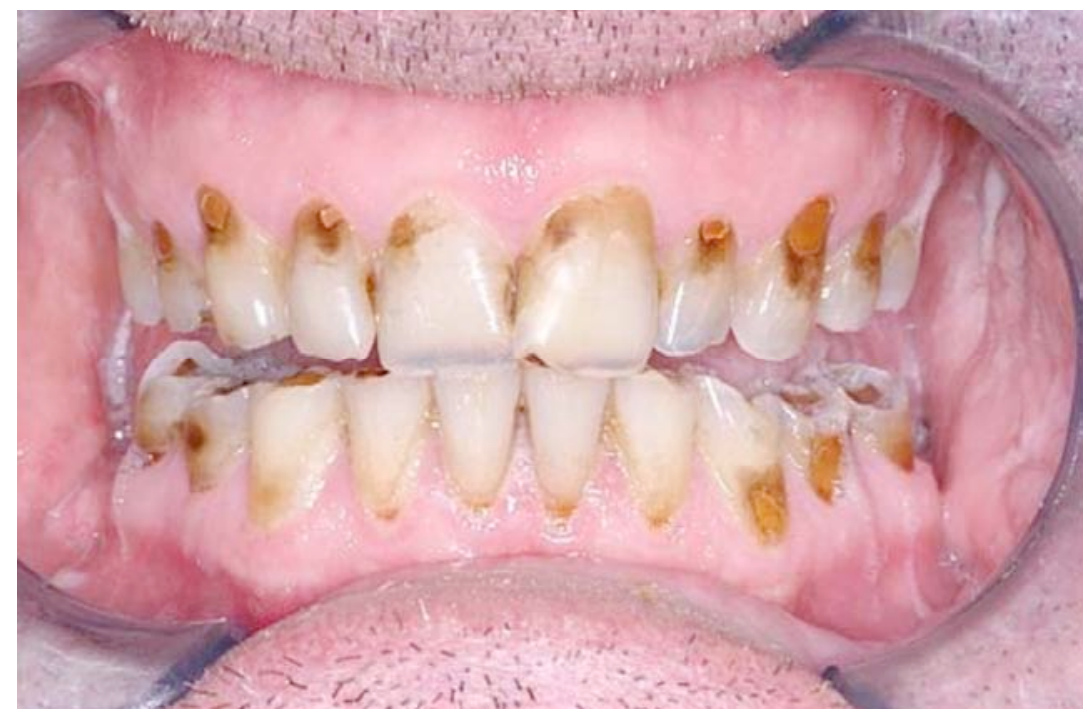

Fig. (3). Post radiotherapy dental caries. 


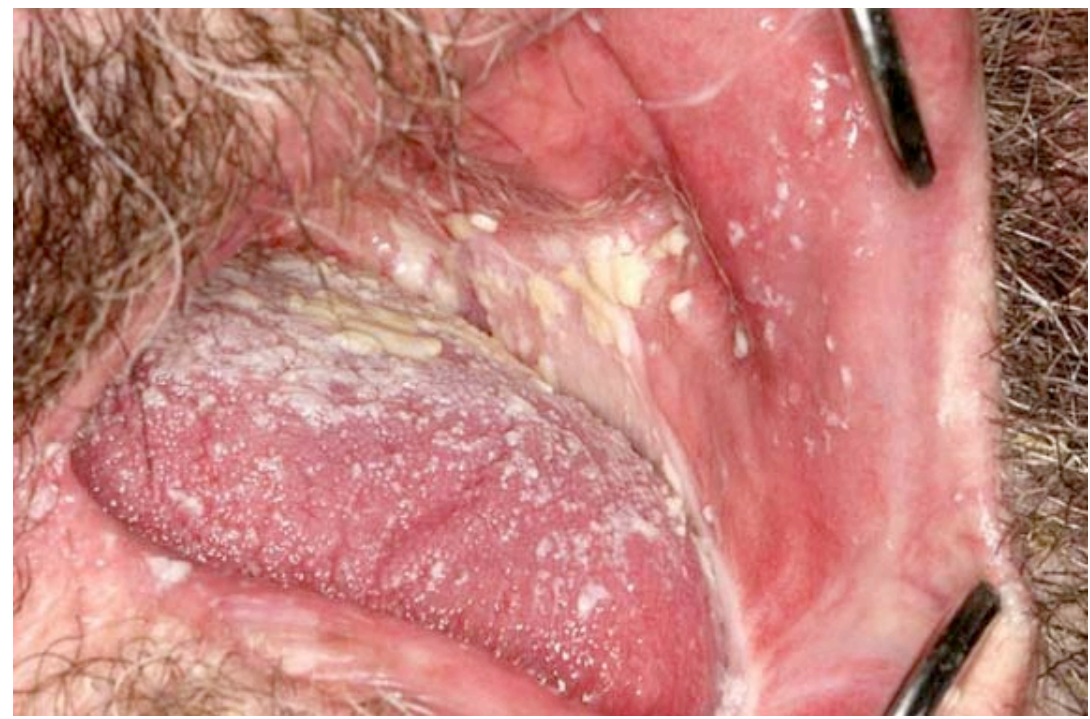

Fig. (4). Oral candidiasis.

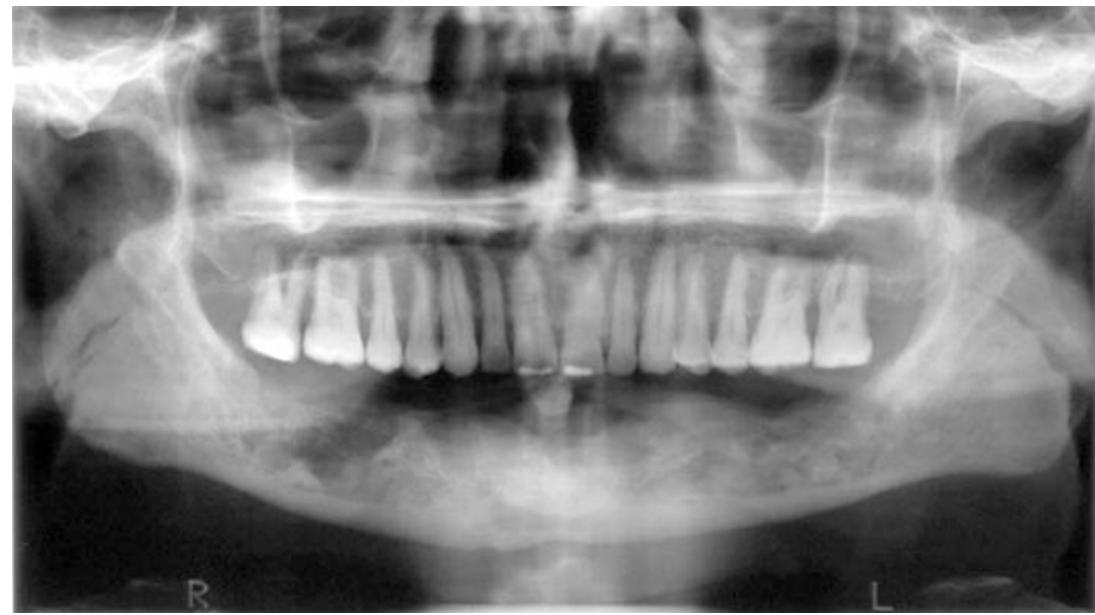

Fig. (5). Osteoradionecrosis of mandible.

(5\% to $15 \%)$ of which remains with that patient for life [13, $24,25]$. Thus, at the time of the dental work-up, implications of radiation therapy to head and neck region need to be carefully explained as well as the importance of regular, life-long dental care. Comprehensive clinical dental examination including radiographic examination is considered essential [22, 23, 26-28].

One of the more difficult questions to answer at the work-up stage pertains to the removal of teeth prior to radiation therapy. Unfortunately, at present, no clear, evidence based guidelines exist to guide decision making concerning the removal of symptomatic and asymptomatic teeth before radiation therapy [21] with consensus existing only at each end of the spectrum i.e. hopeless teeth to be extracted and intact dentition retained [10]. Criteria proposed for extraction of teeth in high dose radiation field include: non-restorable teeth $[10,22,26,28-31]$, teeth exhibiting root caries [10, 31], teeth with root resorption [10], teeth requiring significant restorative endodontic or orthodontic intervention [26], teeth with moderate to severe periodontal disease (pocket depth $>5 \mathrm{~mm}$ ), those with furcation involvement and those with advanced recession $[10,12,22,26,28,29,31]$, teeth demonstrating peri-apical pathology $[10,22,28]$, partially impacted teeth [29] and non-functional teeth [10, 31, 32]. Factors such as dental history, patient cooperation, ability to maintain oral hygiene and prognosis for tumour control also need to be considered [10, 26, 28, 29, 31, 32].

\section{Follow-Up During Cancer Treatment}

During radiation therapy, the most significant problems encountered are those of mucositis, hyposalivation, dysgeusia and oral candidiasis. Patients are managed at that stage with analgesics, including opioids, topical agents such as anaesthetics, anti-inflammatory agents and with emphasis on maintenance of meticulous oral hygiene [33, 34]. Hyposalivation is managed symptomatically with dry mouth products [35]. Oral candidiasis is managed by use of topical and systemic antimycotic agents as well as through meticulous oral hygiene maintenance [35].

\section{Life-Long, Post Treatment, Follow-Up}

Maintaining a life long, optimal level of oral health is the most challenging, yet profoundly rewarding aspect of the dental management of the oral cancer patient. Maintenance of the natural dentition where possible and prevention of osteoradionecrosis, significantly contributes to the preserva- 
tion of oral function and therefore life quality. Stability of the dentition in the challenging dry mouth environment can be ensured by instituting strict preventive protocols consisting of regular dietary counselling [12, 23, 35], use of topical fluoride $[12,23,29,35]$, remineralisation products $[23,35]$, maintenance of meticulous oral hygiene and regular dental examinations and prophylaxis $[18,23,35]$. While substantial effort and commitment is required on the part of the patient in particular, preservation of intact natural dentition post radiation therapy, in the dry mouth environment is possible.

Where the natural dentition cannot be maintained, prosthetic rehabilitation can be undertaken. Infections, trismus and osteoradionecrosis, when present, are usually managed in specialist centres $[21,22]$.

It is well recognised that dental care forms an integral and important part of the multidisciplinary management of oral cancer patients. While numerous studies have been published assessing dentists' knowledge about oral cancer and their ability to detect it [36-45], to the best of the authors' knowledge, to date, no Australian specific studies have been published assessing the dentists' knowledge and clinical expertise regarding dental management of already diagnosed oral cancer patients. In fact only one international study has been found assessing the dentist's knowledge of oral care for cancer patients and this study did not focus specifically on oral cancer patients [46]. Such information is imperative when planning professional education at the undergraduate and postgraduate level to ensure that the dental profession is in fact able to manage this complex patient group and therefore duly contribute to the multidisciplinary care of oral cancer patients.

The aim of this study was to examine actual and selfperceived knowledge and clinical expertise regarding dental management of oral cancer patients receiving radiation therapy among Western Australian dentists. The results of the study are anticipated to provide important information which may form the basis for planning professional education at the undergraduate and postgraduate level.

\section{MATERIALS AND METHODS}

The Australian Dental Association (ADA), WA branch, was contacted and asked to email to all registered Western Australian dentists $(n=1095)$ an invitation to participate in a web-based questionnaire designed to assess their actual and perceived expertise regarding dental management of oral cancer patients receiving radiation therapy. Both dentists and dental specialists are registered with the ADA (WA branch). As the ADA (WA branch) does not differentiate in membership, all dentists were emailed. Survey instructions invited general dentists only to participate $(n=963)$. The SurveyMonkeyTM online survey system was used. Three weeks after the initial invitation was emailed out, a second invitation was emailed from the ADA (WA branch), again inviting the general dentists to participate. The web based questionnaire remained opened to participants for a total of six weeks. An incentive was offered to participants in the form of a restaurant gift voucher.

To assess dentists' knowledge and expertise, actual and perceived knowledge was investigated. Actual knowledge was assessed from a series of objective questions regarding dental management of oral cancer patients receiving radiation therapy to the head and neck region and by using a 6 point Likert scale. Dentists' perceived knowledge was assessed using only the 6 point Likert scale.

Information regarding type of practice (public versus private); practice location (within or outside metropolitan area); year of graduation and number of oral cancer patients treated in the preceding 12 months was also obtained. Anyone who was a dental specialist (i.e., not describing themselves as a general dentist) was excluded.

Responses were extracted into a spreadsheet and converted to a Stata 11dataset for analysis. Open-ended question responses were investigated for themes.

Characteristics of the sample were determined using descriptive analysis, followed by bivariate analysis using a chisquare test to detect possible associations.

Ethics approval was sought and obtained from the University of Western Australia Human Research Ethics Committee.

\section{RESULTS}

This was a questionnaire based observational study. The questionnaire link was emailed to 1095 dentists registered with the Australian Dental Association (WA branch). Both dentists and dental specialists are registered with the Australian Dental Association (WA branch). The Australian Dental Association (WA branch) does not differentiate in membership, but advised there were 98 members who were listed as specialist in their membership. An additional thirty four of the members were classified as retired. A total of 963 members were therefore deemed eligible to participate in the survey. Of the 191 dentists who responded to the questionnaire, 151 completed it in full. Five responders described themselves as specialists and were excluded from analysis. This represents a response rate of $20 \%$. The general characteristics of responders are shown in Table $\mathbf{1}$.

Responses to statements assessing dentist's perceived knowledge are summarised in Table 2. Seventy eight per cent of responders agreed that general dentists should be able to provide dental treatment for oral cancer patients. However, less than half $(44.7 \%)$ indicated that they felt confident treating oral cancer patients or that they felt adequately trained $(42.3 \%)$ to manage oral cancer patients. Only $37.1 \%$ of responders perceived themselves as being up to date in managing oral cancer patients.

The overwhelming majority of responders $(92.9 \%)$ indicated that they were interested in attending continuing education courses on the subject. This was also apparent in the comment section. Only half of responders $(52.2 \%)$ indicated that they always communicate with a patient's radiation oncologist, when asked to assess patients prior to commencement of radiation therapy.

Less than half of all responders (41.7\%) felt confident in giving advice to patients regarding management of acute side-effects of their cancer treatment.

Only $32.9 \%$ of all responders preferred to refer oral cancer patients for a pre-radiation therapy dental assessment. 
Table1. General Characteristic of Responders

\begin{tabular}{|c|c|}
\hline General Characteristic of Responders $(n=186)$ & $\mathbf{n}(\%)$ \\
\hline \multicolumn{2}{|c|}{ Year of graduation $(n=151)^{*}$} \\
\hline $2010-2006$ & $41(27.1 \%)$ \\
\hline $2005-2001$ & $19(12.6 \%)$ \\
\hline $2000-1996$ & $19(12.6 \%)$ \\
\hline $1995-1991$ & $8(5.3 \%)$ \\
\hline $1990-1986$ & $15(10.0 \%)$ \\
\hline Prior to 1985 & $47(31.1 \%)$ \\
\hline Unknown & $2(1.3 \%)$ \\
\hline \multicolumn{2}{|c|}{ Type of practice $(\mathrm{n}=185)^{*}$} \\
\hline Private sector & $166(89.7 \%)$ \\
\hline Public Sector & $19(10.3 \%)$ \\
\hline \multicolumn{2}{|c|}{ Practice location $(\mathrm{n}=184)^{*}$} \\
\hline Within metropolitan Perth & $140(76 \%)$ \\
\hline Outside metropolitan Perth & $44(23.9 \%)$ \\
\hline \multicolumn{2}{|c|}{ Number of oral cancer patients (treated with radiation therapy) seen in the last 12 months ( $\mathrm{n}=152)^{*}$} \\
\hline 0 & $56(36.8 \%)$ \\
\hline 1 & $30(19.7 \%)$ \\
\hline 2 & $34(22.4 \%)$ \\
\hline 3 & $10(6.6 \%)$ \\
\hline 4 & $5(3.3 \%)$ \\
\hline 5 & $4(2.6 \%)$ \\
\hline$>6$ & $8(5.3 \%)$ \\
\hline Unclear\# & $5(3.3 \%)$ \\
\hline
\end{tabular}

*Indicates total number of responders to the question.

\# It was difficult to ascertain participant's response.

Table 2. Responses to Statements Used in the Survey

\begin{tabular}{|c|c|c|c|c|c|c|c|}
\hline \multirow{2}{*}{ Statement } & \multicolumn{7}{|c|}{ Response Rate (\%) } \\
\hline & Strongly Agree & Agree & Neutral & Disagree & Strongly Disagree & Uncertain & Not Applicable \# \\
\hline $\begin{array}{l}\text { "General dentists should be able to } \\
\text { provide dental treatment for oral cancer } \\
\text { patients" }(\mathrm{n}=184)^{*}\end{array}$ & $26.1 \%$ & $51.6 \%$ & $13.6 \%$ & $7.1 \%$ & $1.6 \%$ & $0 \%$ & $0 \%$ \\
\hline $\begin{array}{l}\text { "I am confident in treating oral cancer } \\
\text { patients" }(n=183)^{*}\end{array}$ & $8.7 \%$ & $36.1 \%$ & $23 \%$ & $23 \%$ & $7.1 \%$ & $2.2 \%$ & $0 \%$ \\
\hline $\begin{array}{l}\text { "I feel I am adequately trained to man- } \\
\text { age oral cancer patients" }(\mathrm{n}=182)^{*}\end{array}$ & $6.0 \%$ & $36.3 \%$ & $26.9 \%$ & $20.9 \%$ & $8.2 \%$ & $1.6 \%$ & $0 \%$ \\
\hline $\begin{array}{l}\text { "I feel I am up to date in managing oral } \\
\text { cancer patients" }(\mathrm{n}=183)^{*}\end{array}$ & $3.8 \%$ & $33.3 \%$ & $27.9 \%$ & $23.0 \%$ & $8.2 \%$ & $3.8 \%$ & $0 \%$ \\
\hline $\begin{array}{l}\text { "I am interested in attending continuing } \\
\text { education courses on the management } \\
\text { of oral cancer patients" }(n=183)^{*}\end{array}$ & $47.5 \%$ & $45.4 \%$ & $6.0 \%$ & $0.5 \%$ & $0.5 \%$ & $0 \%$ & $0 \%$ \\
\hline $\begin{array}{l}\text { "I always communicate with a patient's } \\
\text { radiation oncologist, when asked to } \\
\text { assess patients prior to commencement } \\
\text { of radiation therapy" }(\mathrm{n}=180)^{*}\end{array}$ & $26.1 \%$ & $26.1 \%$ & $16.1 \%$ & $6.7 \%$ & $0.6 \%$ & $5.6 \%$ & $18.9 \%$ \\
\hline
\end{tabular}


Table 2. contd....

\begin{tabular}{|c|c|c|c|c|c|c|c|}
\hline \multirow{2}{*}{ Statement } & \multicolumn{7}{|c|}{ Response rate (\%) } \\
\hline & Strongly Agree & Agree & Neutral & Disagree & Strongly Disagree & Uncertain & Not Applicable \# \\
\hline $\begin{array}{l}\text { "I feel confident in giving advice to } \\
\text { patients regarding management of acute } \\
\text { side-effects of their cancer treatment" } \\
(\mathrm{n}=180)^{*}\end{array}$ & $6.1 \%$ & $35.6 \%$ & $18.9 \%$ & $21.1 \%$ & $2.8 \%$ & $3.9 \%$ & $11.7 \%$ \\
\hline $\begin{array}{c}\text { "Iprefer to refer oral cancer patients for } \\
\text { pre-radiation therapy dental assess- } \\
\text { ment" }(\mathrm{n}=179)^{*}\end{array}$ & $7.8 \%$ & $25.1 \%$ & $25.1 \%$ & $26.3 \%$ & $4.5 \%$ & $2.2 \%$ & $8.9 \%$ \\
\hline $\begin{array}{l}\text { "Ifeel confident in giving advice to } \\
\text { patients regarding management of } \\
\text { chronic complications of their cancer } \\
\text { treatment" }(\mathrm{n}=179)^{*}\end{array}$ & $9.5 \%$ & $42.5 \%$ & $13.4 \%$ & $19.0 \%$ & $1.7 \%$ & $4.5 \%$ & $9.5 \%$ \\
\hline $\begin{array}{l}\text { Responses to statement "I do not be- } \\
\text { lieve that dental breakdown can be } \\
\text { prevented in oral cancer patients that } \\
\text { have been treated with radiation ther- } \\
\text { apy" }(\mathrm{n}=179)^{*}\end{array}$ & $2.2 \%$ & $3.4 \%$ & $12.3 \%$ & $52.5 \%$ & $21.2 \%$ & $2.8 \%$ & $5.6 \%$ \\
\hline
\end{tabular}

* Indicates number of participants who responded to the statement.

\# Indicates not applicable as the participant does not treat oral cancer patients.

Table 3. Answers to question: Do you/would you Routinely Communicate with other Clinicians Involved in the Care of Oral Cancer Patients, and if so, with Whom? $n=145$

\begin{tabular}{|c|c|}
\hline $\begin{array}{l}\text { Do you/would you Routinely Communicate with other Clinicians Involved in the Care of Oral Cancer } \\
\text { Patients, and if so, with whom? }\end{array}$ & $\mathbf{n}(\%)$ \\
\hline Yes & \multirow[t]{14}{*}{$102(70.3 \%)$} \\
\hline General Medical Practitioner (45)* & \\
\hline Oral Medicine Specialist (36)* & \\
\hline Oral Pathologist (7)* & \\
\hline Oral Surgeon $(23)^{*}$ & \\
\hline Other Dental Specialists e.g. Periodontist / Prosthodontist (10)* & \\
\hline Peers $(7)^{*}$ & \\
\hline Pain Specialist (2)* & \\
\hline Oncologist $(30)^{*}$ & \\
\hline ENT Specialist (5)* & \\
\hline Dietician $(4)^{*}$ & \\
\hline Speech Pathologist (1)* & \\
\hline Physiotherapist (1)* & \\
\hline Other $(5)^{*}$ & \\
\hline No & $28(19.3 \%)$ \\
\hline Response unclear\# & $15(10.3 \%)$ \\
\hline
\end{tabular}

* Indicates frequency among those participants who responded 'yes'.

\# It was difficult to ascertain whether the participant's response was 'yes' or 'no'.

Only half of responders (52\%) felt confident in giving advice to patients regarding management of chronic complications of their cancer treatment.

The overwhelming majority $(73.7 \%)$ of responders were of the opinion that dental breakdown can be prevented in oral cancer patients that have been treated with radiation therapy.

Only $25.7 \%$ of responders preferred to refer patients to a specialist for management post completion of oral cancer treatment.
When responses were compared between those provided by dentists working within and outside of metropolitan Perth; no statistically significant associations were observed for any of the above statements.

The majority of responders $(70.3 \%)$ indicated that they would communicate with other clinicians involved in the care of oral cancer patients, with the general medical practitioner being the most commonly identified (Table 3 ).

Of the responders who indicated that they routinely communicate (or would communicate) with the patient's 
Table 4. Answers to Question: If you Routinely Communicate (or Would Communicate) with the Patient's Radiation Oncologist when Asked to Assess Patients Prior to Commencement of Radiation Therapy, what Information do you/would you Request from the Radiation Oncologist? $n=145$

\begin{tabular}{|c|c|}
\hline $\begin{array}{c}\text { If you Routinely Communicate (or would Communicate) with the Patient's Radiation Oncologist when asked to } \\
\text { Assess Patients Prior to Commencement of Radiation Therapy, what Information do you/would you Request } \\
\text { from the Radiation Oncologist? }\end{array}$ & n (\%) \\
\hline \hline Field of radiation* & $90(62.1 \%)$ \\
\hline Dose of radiation therapy to be administered* & $30(20.1 \%)$ \\
\hline Date of commencement of radiation therapy* & $15(10.3 \%)$ \\
\hline Expected side-effects* & $9(6.2 \%)$ \\
\hline Nature of overall cancer treatment plan* & $18(12.4 \%)$ \\
\hline Patient prognosis* & $2(1.4 \%)$ \\
\hline Medical history* & $7(4.8 \%)$ \\
\hline Don't know what information to request* & $26(17.9 \%)$ \\
\hline Response unclear or did not answer the question\#* & \\
\hline
\end{tabular}

* Indicates frequency among those participants who responded.

\# It was difficult to ascertain what the participant's response was.

Radiation Oncologist, when asked to assess patients prior to commencement of radiation therapy; majority $(62.1 \%)$ indicated that they would request information pertaining to the extent of radiation therapy fields (Table 4).

All responders correctly identified the short and long term consequences of radiation therapy to the head and neck region (Table 5) and all responders provided useful advice which can be given to post radiation therapy patients to help them maintain optimal level of oral health (Table 6).

\section{DISCUSSION}

One hundred and ninety one general dentists participated in this questionnaire based observational study. Our response rate of $20 \%$ was low, but within the reported response rates of dentist to questionaries (17-100\%) [47]. Low response rates are not uncommon among medical practitioners and similarly among dentists [47, 48]. Low interest and importance of the subject matter have been attributed to low response rates as well as the use of online versus postal surveys $[47,48]$. The limited role that dentists appear to play in patient education regarding oral cancer, its signs, symptoms and risk factors may be due to low interest or their limited experience [7, 8]. Factors which have been associated with favourable response rates include: advance notification of the survey; official sponsorship of the survey; personalization of correspondence; anonymity and confidentiality; cover letter's composition; offers of incentives and repeated followup [47, 49].

We have tried to maximise response rates by providing advance notification of the survey; providing an incentive of a restaurant gift voucher and by ensuring anonymity and confidentiality. The cover letter was carefully worded and involvement of the University of Western Australia was clearly stated. An online approach was deemed most cost effective. All Western Australian dentists were targeted by the survey due to the relatively small numbers of oral cancer patients in WA. Targeting all dentists registered with the ADA (WA branch) increased chances of engaging dentists who currently manage oral cancer patients.
Our low response rate may be partly explained by the fact that oral cancer is not a common disease in Western Australia, with only about 300 cases diagnosed annually in WA, and therefore dental management of such patients may not be of great interest to many general dentists [2].

While it may be argued that oral cancer is not a common disease, and therefore the need for general dentists to know how to manage these patients may be questioned, one must remember the rising incidence of this disease. It is also important to consider that oral cancer patients are not the only patient group who receive radiation therapy to the head and neck region. Over 400 patients are annually diagnosed in Western Australia with 'head and neck cancer' (ICD10 codes: C00-C119, C300-C329), not taking into account the numerous skin cancers which also affect this region [2]. Many of those patients potentially receive radiation therapy to the head and neck and are in need of the same dental care. Unfortunately cancer centres often lack the resources to provide comprehensive dental care. As a result, it is often the case that dental care must be provided by the patient's general dentist. Patients may also prefer to be treated by their own dentist and may find it inconvenient to travel significant distances to receive specialist care. It is therefore important that general dentists are able to correctly manage oral cancer patients.

While the overwhelming majority of responders indicated that general dentists should be able to provide dental treatment to oral cancer patients, generally the responders did not feel confident or adequately trained in being able to provide the necessary dental treatment. These results suggest that while responders recognize their role in the management of oral cancer patients, they also perceive themselves as limited in being able to fulfil this role. This perception may be linked to inadequate clinical training of dentists, which is likely related to the low incidence of oral cancer in Western Australia, and is therefore of low priority. Low incidence of this disease also impacts on the limited exposure of dentists to oral cancer patients and consequently on their ability to 
Table 5. Answers to Question: What do you Perceive to be the Short and Long Term Complications of Radiation Therapy to the Head and Neck Region? $n=150$

\begin{tabular}{|c|c|}
\hline $\begin{array}{l}\text { What do you Perceive to be the Short and Long Term Complications of Radiation Therapy to the } \\
\text { Head and Neck Region? }\end{array}$ & n $(\%)$ \\
\hline Xerostomia* & $120(80.0 \%)$ \\
\hline Increased risk of dental caries* & $75(50.0 \%)$ \\
\hline Osteoradionecrosis of the jaw* & $40(26.7 \%)$ \\
\hline Mucositis* & $32(21.3 \%)$ \\
\hline Periodontal diseases* & $28(18.7 \%)$ \\
\hline Loss/altered loss of taste sensation* & $19(12.7 \%)$ \\
\hline Other oral infections including fungal $*$ & $14(9.3 \%)$ \\
\hline Difficulties with prostheses* & $13(8.7 \%)$ \\
\hline Nutrition issues and weight loss* & $11(7.3 \%)$ \\
\hline Dysphagia* & $9(6.0 \%)$ \\
\hline Impaired wound healing* & $9(6.0 \%)$ \\
\hline Oral pain* & $9(6.0 \%)$ \\
\hline Difficulty chewing* & $8(5.3 \%)$ \\
\hline Oral ulcers* & $8(5.3 \%)$ \\
\hline Oral scarring and limited mouth opening* & $7(4.7 \%)$ \\
\hline Reduced quality of life* & $4(2.7 \%)$ \\
\hline Burning Mouth Syndrome* & $2(1.3 \%)$ \\
\hline Dry eyes* & $1(0.7 \%)$ \\
\hline Impact on thyroid gland* & $1(0.7 \%)$ \\
\hline Increased risk of other cancers* & $1(0.7 \%)$ \\
\hline Speech issues* & $1(0.7 \%)$ \\
\hline Psychological issues* & $1(0.7 \%)$ \\
\hline Response unclear or did not answer the question\#* & $13(8.7 \%)$ \\
\hline
\end{tabular}

* Indicates frequency among those participants who responded.

\# It was difficult to ascertain what the participant's response was.

Table 6. Answers to Question: What Advice do you/would you Routinely give to Post Radiation Therapy Patients to Help them Maintain Optimal Level of Oral Health? $n=152$

\begin{tabular}{|c|c|}
\hline $\begin{array}{c}\text { What advice do you/would you Routinely give to Post Radiation Therapy Patients to Help them Maintain Optimal } \\
\text { Level of Oral Health? }\end{array}$ & $\mathbf{n}(\%)$ \\
\hline \hline Regular dental check-ups* & $85(55.9 \%)$ \\
\hline Dietary advice* & $80(52.6 \%)$ \\
\hline Oral hygiene instructions* & $50(32.9 \%)$ \\
\hline Use of topical fluoride* & $40(26.3 \%)$ \\
\hline Use of dry mouth products* & $28(18.4 \%)$ \\
\hline Increased water intake* & $17(11.2 \%)$ \\
\hline Use of CPP-ACP (Casein Phosphopeptide-Amorphous Calcium Phosphate)* & $8(5.3 \%)$ \\
\hline Use of mouth wash* & $6(3.9 \%)$ \\
\hline Use of sugar free chewing gum* & $4(2.6 \%)$ \\
\hline Use of oil to lubricate mouth* & $3(2.0 \%)$ \\
\hline Avoidance of alcohol and caffeine* & $2(1.3 \%)$ \\
\hline Advice on risk of osteoradionectrosis of the jaw* & \\
\hline
\end{tabular}


Table 6. contd....

\begin{tabular}{|c|c|}
\hline $\begin{array}{c}\text { What advice do you/would you Routinely give to Post Radiation Therapy Patients to Help them Maintain Optimal } \\
\text { Level of Oral Health? }\end{array}$ & n (\%) \\
\hline \hline Advice on pain control* & $1(0.7 \%)$ \\
\hline Advice on quitting smoking* & $1(0.7 \%)$ \\
\hline Use of humidifier during sleep * & $1(0.7 \%)$ \\
\hline Physiotherapy* & $1(0.7 \%)$ \\
\hline Unclear** & $4(2.6 \%)$ \\
\hline
\end{tabular}

* Indicates frequency among those participants who responded.

\# It was difficult to ascertain what the participant's response was.

gain experience and confidence. This is in line with our finding that almost $90 \%$ of participants had treated less than two oral cancer patients in the preceding 12 months.

All responders correctly identified at least one long term complication of radiation therapy to the head and neck region and all would provide some useful advice. However, only half would provide dietary and oral hygiene instruction and less than a third would provide advice on the use of fluoride or remineralization products - this is despite the fact that the majority of dentists were of the opinion that dental breakdown in these patients can be prevented. Maintenance of natural dentition and prevention of osteoradionecrosis, significantly contributes to the preservation of oral function and quality of life. Stability of dentition in the dry mouth environment is only possible by instituting strict preventive protocols comprising of regular dietary counselling [12, 23, 35], use of topical fluoride [12, 23, 29, 35], remineralisation products [23, 35], maintenance of meticulous oral hygiene and regular dental examinations and prophylaxis [18, 23, 35]. Such preventive advice should be given every time and to all patients [35]. The limited advice provided by responders reflects deficiencies in their understanding of the long term complications of radiation therapy to the head and neck region and of what is required on the part of the patient and clinician to enable that patient to maintain an optimum level of oral health in the long term. This may be explained by inadequate or infrequent training of dentists in this area.

Ninety three per cent of responders indicated that they were interested in attending continuing education courses on the subject. These results suggest an apparent need for further, clinically relevant, training of dentists in this area and that over-whelming majority of responders recognize deficiencies in their knowledge and are interested in advancing their expertise in the field.

Interestingly, less than one third of all responders preferred to refer oral cancer patients to specialists for pre-radiation therapy dental assessment or for management post completion of cancer treatment. This apparent paradox may be explained by the uncertainty surrounding referral pathways.

Only half of responders $(52.2 \%)$ indicated that they always communicate with a patient's radiation oncologist, when asked to assess patients prior to commencement of radiation therapy. When asked "If you routinely communicate (or would communicate) with the patient's Radiation Oncologist when asked to assess patients prior to commencement of radiation therapy, what information do you/would you request from the Radiation Oncologist?", only $62 \%$ of responders indicated that they would enquire about the extent of irradiated field and less than one third indicated that they would enquire about the dose of radiation therapy to be administered. Communication with the radiation oncologist is essential to establish extent of irradiated field and to identify teeth in the irradiated field. This information aids decision making regarding prophylactic removal of teeth $[10,12,22,26,28,29,31,32]$; shielding of metallic restorations from radiation back scatter [50] and aids discussion with the patient regarding expected complications of treatment and their severity. This lack of communication may be attributed to participants' incomplete knowledge of radiation therapy; or may be the result of difficulties encountered when trying to communicate with the patient's oncologist; or may be the result of participants' perceived ignorance of dental problems of the medical community.

When asked "do you/would you routinely communicate with other clinicians involved in the care of oral cancer patients, and if so, with whom?", only four (3\%) responders indicated that they would communicate with the patient's dietician. Given that a link between cariogenic diet and dental caries is well established [51], and that consumption of acidic foods is associated with dental erosion [52], and in light of the fact that extractions as a result of dental breakdown, place post radiation therapy patients at risk ofosteoradionecrosis [25] it is important to minimize consumption of cariogenic and acidic foods in dentate patients. This often proves challenging as at the same time consideration must be given to the overall impact of dietary restrictions on patient's nutritional status and how much the patient is compromised from other side effects, such as dysphagia, dysgeusia and odynophagia, which may impact food choices $[15,16]$. Malnutrition is a significant problem with up to half of head and neck cancer patients presenting malnourished at the time of their cancer diagnosis and is in itself associated with increased mortality and morbidity [53]. Nutritional advice to oral cancer patients therefore cannot be given lightly and there is a great need for dentists and dieticians to work closely together. This can only occur if the problem is recognized by dentists. The results of this study highlight a lack of understanding by participants of the nutritional impacts of oral cancer and its treatment and / or assumption on the part of the responders that correct dietary advice is given to dentate cancer patients by other clinicians involved in their care. Unfortunately patients are often advised to consume sugar containing meal supplements, in an attempt to maintain 
weight, therefore a constant dialogue with a dietician is imperative in an effort to prevent dental breakdown [53].

In summary, general dentists who took part in the study appeared to possess some knowledge regarding dental management of oral cancer patients treated with radiation therapy. The majority of responders however identified deficiencies in their knowledge and willingness to participate in continuing education programs. In view of the rising incidence of oral cancer in Western Australia, efforts should be made to provide more clinically relevant training to dentists in this area.

The main limitation of this study is the low response rate and response bias needs to be considered. It has been proposed that non responders may be less aware or less interested in the subject of the questionnaire [47]. Between 2009 to 2011, the Western Australian Health Department's WA Cancer and Palliative Care Network has been running a "Head and Neck Cancer Education Road Show" across Western Australia in an attempt to raise awareness of oral cancer including diagnosis, referral pathways and treatment. This education program may have influenced responders.

\section{CONCLUSION}

General dentists who took part in the study appeared to possess some knowledge regarding dental management of oral cancer patients treated with radiation therapy. There were deficiencies in knowledge identified for some responders in their knowledge and willingness to participate in continuing education programs. In view of the rising incidence of oral cancer in Western Australia, efforts should be made to provide more clinically relevant training to dentists in this area.

\section{CONFLICT OF INTEREST}

The authors confirm that this article content has no conflicts of interest.

\section{ACKNOWLEDGEMENTS}

The authors would like to thank the Australian Dental Association (WA branch) for facilitating this study and the participants who kindly gave their time to participate.

\section{REFERENCES}

[1] Australian Institute of Health and Welfare 2010. Cancer in Australia 2010: an overview. Cancer series no. 60. Cat. no. CAN 56. Canberra: AIHW.

[2] Threlfall TJ, Thompson JR. Cancer incidence and mortality in Western Australia 2009. Department of Health, Western Australia, Perth. 2010; Statistical Series Number 91.

[3] Johnson NW, Jayasekara P, Hemantha AA, Amarasinghe K. Squamous cell carcinoma and precursor lesions of the oral cavity: epidemiology and aetiology. Periodontol 2000 2011; 57: 19-37.

[4] Hocking JS, Stein A, Conway EL, Regan D et al. Head and Neck Cancer in Australia between 1982 and 2005 show increasing incidence of potentially HPV-associated oropharyngeal cancers. Br J Cancer 2011; 104: 886-91.

[5] Shaw RJ, Pace-Balzin A, Butterworth C. Contemporary clinical management of oral squamous cell carcinoma. Periodontol 2000 2011; 57: 89-101.

[6] Spencer KR, Fergurson JW, Wiesenfield D. Current concepts in the management of oral squamous cell carcinoma. Aust Dent J 2002; 47: 284-9.

[7] Villa A, Kreimer AR, Pasi M, Polimeni A et al. Oral cancer knowledge: a survey administered to patients in dental departments at large italian hospitals. J Cancer Educ 2011; 26: 505-9.
Park JH, Slack-Smith LM, Frydrych AM, et al. Knowledge and perceptions regarding oral and pharyngeal carcinoma among adult dental patients. Aust Dent J 2011; 56: 284-9.

[9] Devadiga A, Prasad KV. Knowledge about oral cancer in Adults attending a dental hospital in India. Asian Pacific J Cancer Prev 2010; 11: 1609-13.

[10] Schiodt M, Hermund NU. Management of oral disease prior to radiation therapy. Support Care Cancer 2002; 10: 40-3.

[11] Fischer DJ, Epstein JB. Management of patients who have undergone head and neck cancer therapy. Dent Clin N Am 2008; 52: 3960.

[12] Kielbassa AM, Hinkelbein W, Hellwig E, Meyer-Luckel H. Radiation-related damage to dentition. Lancet Oncol 2006 ; 7: 326-35.

[13] Annane D, Depondt J, Aubert P, et al. Hyperbaric oxygen therapy for radionecrosis of the jaw: a randomized, placebo-controlled, double-blind trial from the ORN96 study group. J Clin Oncol 2004; 22: 4893-900.

[14] Pace-Balzan A, Shaw RJ, Butterworth C. Oral rehabilitation following treatment for oral cancer. Periodontol 2000 2011; 57: 10217.

[15] Ravasco P, Monteiro Grillo I, Camilo M. Cancer wasting and quality of life react to early individualized nutritional counselling. Clin Nutr 2007; 26: 7-15.

[16] Nourissat A, Bairati I, Fortin A, et al. Predictors of weight loss during radiotherapy in patients with stage I or II head and neck cancer. Cancer 2010; 116: 2275-83.

[17] Andrews N, Griffiths C. Dental complications of head and neck radiotherapy: Part1. Aust Dent J 2001; 46: 88-94.

[18] Shiborski CH, Hodgson TA, Ship JA, Schiodt M. Management of salivary hypofunction during and after radiotherapy. Oral Surg Oral Med Oral Pathol Oral Radiol Endod 2007; 103(suppl 1): S66.e1S66.e19.

[19] Ben-David MA, Diamante M, Radawski JD, et al. Lack of osteoradionecrosis of the mandible after intensity-modulated radiotherapy for head and neck cancer: likely contributions of both dental care and improved dose distributions. Int J Radiat Oncol Biol Phys 2007; 68: 396-402.

[20] Studer G, Glanzmann SG, Studer SP. Risk-adapted dental care prior to intensity-modulated radiotherapy (IMRT). Schweiz Monatsschr Zahnmed 2011; 121: 216-29.

[21] Murphy BA, Gilbert J. Oral cancers: supportive care issues. Periodontol 2000 2011; 57: 118-31.

[22] Joshi VK. Dental treatment planning and management for the mouth cancer patient. Oral Oncol 2010; 46: 457-79.

[23] Walsh LJ. Clinical assessment and management of the oral environment in the oncology patient. Aust Dent J 2010; 55(1 Suppl): 66-77.

[24] Nabil S, Samman N. Incidence and prevention of osteoradionecrosis after dental extraction in irradiated patients: a systematic review. Int J Oral Maxillofac Surg 2011; 40: 229-43.

[25] Madrid C, Abarca M, Bouferrache K. Osteoradionecrosis: an update. Oral Oncol 2010; 46: 471-4.

[26] Epstein JB, Stevenson-Moore P. Periodontal disease and periodontal management in patients with cancer. Oral Oncol 2001; 37: 6139.

[27] Brennan MT, Woo SB, Lockhart PB. Dental treatment planning and management in the patient who has cancer. Dent Clin N Am 2008; 52: 19-37.

[28] Andrews N, Griffiths C. Dental complications of head and neck radiotherapy: Part2. Aust Dent J 2001; 46: 174-82.

[29] Sulaiman F, Huryn JM, Zlotolow IM. Dental extractions in the irradiated head and neck patient: a retrospective analysis of memorial sloan-kettering cancer centre protocols, criteria and end results. J Oral Maxillofac Surg 2003; 61: 1123-31.

[30] Wahl MJ. Osteoradionecrosis prevention myths. Int J Radiat Oncol Biol Phys 2006; 64: 661-9.

[31] Koga DH, Salvajoli JV, Alves FA. Dental extractions and radiotherapy in head and neck oncology: review of the literature. Oral Dis 2008; 14: 40-4.

[32] Tong CA, Leung AC, Cheng JC, Sham J. Incidence of complicated healing and osteoradionecrosis following tooth extraction in patients receiving radiotherapy for treatment of nasopharyngeal carcinoma. Aust Dent J 1999; 44: 187-94.

[33] Peterson DE. Management of oral and gastrointestinal Mucositis: ESMO clinical recommendations. Ann Oncol 2008; 19 (Suppl 2): ii122-ii5. 
[34] Worthington HV, Clarkson JE, Bryan G, et al. Interventions for preventing oral mucositis for patients with cancer receiving treatment. Cochrane Database Syst Rev 2011, Issue 4. Art. No.: CD000978.

[35] Meurman JH, Gronroos L. Oral and dental health care of oral cancer pateints: Hyposalivation, caries and infections. Oral Oncol 2010; 46: 464-7.

[36] Brocklehurst PR, Baker SR, Speight PM. A qualitative study examining the experience of primary care dentists in the detection and management of potentially malignant lesions. 1. Factors influencing detection and the decision to refer. Br Dent J 2010; 208(2): E3, 72-3.

[37] Leao JC, Goes P, Sobrinho CB, Porter S. Knowledge and clinical expertise regarding oral cancer among Brazilian dentists. Int J Oral Maxillofac Surg 2005; 34: 436-9.

[38] Hertrampf K, Wiltfang J, Koller M, Klosa K, Wenz HJ. Dentist's perspectives on oral cancer: a survey in Northern Germany and a comparison with international data. Eur J Cancer Prev 2010: 19: 144-52.

[39] Colella G, Gaeta GM, Moscariello A, Angelillo IF. Oral cancer and dentists: knowledge, attitudes and practices in Italy. Oral Oncol 2008; 44: 393-9.

[40] Applebaum E, Ruhlen TN, Kronenberg FR, Hayes C, Peters ES. Oral cancer knowledge, attitudes and practices. J Am Dent Assoc 2009; 140(4): 461-7.

[41] Yellowitz JA, Goodman HS. Assessing physicians' and dentists' oral cancer knowledge, opinions and practices. J Am Dent Assoc 1995; 126: 53-60.

[42] Yellowita JA, Horwitz AM, Drury TF, Goodman HS. Survey of US dentists' knowledge and opinions about oral pharyngeal cancer. J Am Dent Assoc 2000; 131: 653-61.

[43] Horwitz AM, Siriphant P, Sheikh A, Child WL. Perspectives of Maryland dentists on oral cancer. J Am Dent Assoc 2001; 132: 6572.
[44] Clovis JB, Horwitz AM, Poel DH. Oral and pharyngeal cancer: knowledge and opinions of dentists in British Columbia and Nova Scotia. J Can Dent Assoc 2002; 68(7): 417-20.

[45] Alonge OK, Narendran S. Oral cancer knowledge and practices of dentists along the Texax-Mexico border. J Cancer Educ 2004; 19: 6-11.

[46] Barker GJ, Epstein JB, Williams KB, Gorsky M, Raber-Durlacher JE. Current practice and knowledge of oral care for cancer patients: a survey of supportive health care providers. Support Care Cancer 2005; 13: 32-41.

[47] Tan RT, Burke FJT. Response rates to questionnaires mailed to dentists: a review of 77 publications. Int Dent J 1997; 47: 349-54.

[48] Crouch S, Robinson P, Pitts M. A comparison of general practitioner response rates to electronic and postal surveys in the setting of the national STI prevention program. Aust NZ J Public Health 2011; 35: 187-9.

[49] Rikard-Bell G, Ward J. Maximizing response rates to a survey of dentists: a randomized trial. Aust Dent J 2000; 45: 46-8.

[50] Farahani M,Eichmiller FC, McLaughlin WL. Measurement of absorbed doses nearmetal and dental material interfaces irradiated by $\mathrm{X}$ - and gamma-ray therapy beams. Phys Med Biol 1990; 35: 369-85.

[51] Hara AT, Zero DT. The caries environment: saliva, pellicle, diet, and hard tissue ultrastructure. Dent Clin North Am 2010; 54: 45567.

[52] Magalhaes AC, Wiehand A, Rios D, Honorio HM, Buzalaf MA. Insights into preventive measures for dental erosion. J Appl Oral Sci 2009; 17: 75-86.

[53] Lee H, Havrila C, Bravo V, et al. Effect of oral nutritional supplementation on weight loss and percutaneous endoscopic gastrostomy tube rates in patients treated with radiotherapy for oropharyngeal carcinoma. Support Care Cancer 2008; 16: 285-9

\author{
Received: July 15, 2012 \\ Revised: September 09, 2012 \\ Accepted: October 12, 2012 \\ (C) Frydrych et al.; Licensee Bentham Open. \\ This is an open access article licensed under the terms of the Creative Commons Attribution Non-Commercial License \\ (http://creativecommons.org/licenses/by-nc/3.0/) which permits unrestricted, non-commercial use, distribution and reproduction in any medium, provided the
} work is properly cited. 